\title{
Modeling the influence of Greenland ice sheet melting on the Atlantic meridional overturning circulation during the next millennia
}

\author{
E. Driesschaert, ${ }^{1}$ T. Fichefet, ${ }^{1}$ H. Goosse,${ }^{1}$ P. Huybrechts, ${ }^{2}$ I. Janssens, ${ }^{2}$ A. Mouchet, ${ }^{3}$ \\ G. Munhoven, ${ }^{3}$ V. Brovkin, ${ }^{4}$ and S. L. Weber ${ }^{5}$ \\ Received 8 February 2007; revised 28 March 2007; accepted 13 April 2007; published 24 May 2007.
}

[1] A three-dimensional Earth system model of intermediate complexity including a dynamic ice sheet component has been used to investigate the long-term evolution of the Greenland ice sheet and its effects on the Atlantic meridional overturning circulation (AMOC) in response to a range of stabilized anthropogenic forcings. Our results suggest that the Greenland ice sheet volume should experience a significant decrease in the future. For a radiative forcing exceeding $7.5 \mathrm{~W} \mathrm{~m}^{-2}$, the modeled ice sheet melts away within 3000 years. A number of feedbacks operate during this deglaciation, implying a strong nonlinear relationship between the radiative forcing and the melting rate. Only in the most extreme scenarios considered, the freshwater flux from Greenland into the surrounding oceans (of ca. $0.1 \mathrm{~Sv}$ during a few centuries) induces a noticeable weakening of the AMOC in the model. Citation: Driesschaert, E., T. Fichefet, H. Goosse, P. Huybrechts, I. Janssens, A. Mouchet, G. Munhoven, V. Brovkin, and S. L. Weber (2007), Modeling the influence of Greenland ice sheet melting on the Atlantic meridional overturning circulation during the next millennia, Geophys. Res. Lett., 34, L10707, doi:10.1029/2007GL029516.

\section{Introduction}

[2] It is now well recognized that anthropogenic emissions of greenhouse gases into the atmosphere have significantly contributed to the global warming of the Earth surface observed during the past 50 years [Intergovernmental Panel on Climate Change (IPCC), 2001]. These anthropogenic emissions are expected to continue in the future and the Earth surface temperature is projected to further increase. Moreover, climate models predict that the warming at northern high latitudes will be larger than the global average owing to positive feedbacks involving, in particular, snow and sea ice [e.g., Holland and Bitz, 2003]. There is therefore growing concern about the future mass balance of the Greenland ice sheet. The entire melting of this ice sheet would raise the global mean sea level by approximately 7 meters and might induce additional changes in the climate

\footnotetext{
${ }^{1}$ Institut d'Astronomie et de Géophysique Georges Lemaître, Université Catholique de Louvain, Louvain-la-Neuve, Belgium.

${ }^{2}$ Departement Geografie, Vrije Universiteit Brussel, Brussels, Belgium.

${ }^{3}$ Laboratoire de Physique Atmosphérique et Planétaire, Institut d'Astrophysique et de Géophysique, Université de Liège, Liège, Belgium.

${ }^{4}$ Climate Systems Research Department, Potsdam Institute for Climate Impact Research, Potsdam, Germany.

${ }^{5}$ Royal Netherlands Meteorological Institute, De Bilt, Netherlands.
}

Copyright 2007 by the American Geophysical Union. 0094-8276/07/2007GL029516\$05.00 system, such as a weakening of the AMOC through the freshening effect of the ice sheet meltwater.

[3] The influence of future climate changes on the Greenland ice sheet has been investigated by running ice sheet models in off-line mode [e.g., Huybrechts and de Wolde, 1999; Greve, 2000; Gregory et al., 2004]. These studies suggest that, if the annual mean temperature in Greenland increases by more than about $3^{\circ} \mathrm{C}$, the ice sheet is likely to loose mass. On the other hand, the climatic impacts of a Greenland deglaciation have previously been examined by using climate models in which the ice sheet was artificially removed [e.g., Dethloff et al., 2004; Lunt et al., 2004; Toniazzo et al., 2004]. Large changes in atmospheric circulation, temperature and precipitation over Greenland and the adjacent oceans were reported. An important drawback of all the above-mentioned studies is that only part of the interactions existing between the Greenland ice sheet and climate were accounted for. In particular, none of them included the effects of the freshwater flux from the melting ice sheet on the AMOC.

[4] A few climate change projections have been performed with coupled climate-ice sheet models [Loutre, 1995; Huybrechts et al., 2002; Fichefet et al., 2003; Ridley et al., 2005; Winguth et al., 2005]. However, the results substantially differ from one study to another, especially regarding the role of the Greenland ice sheet in modulating the future strength of the AMOC. One potential cause of this discrepancy is that these studies used different forcing scenarios. Our goal here is to analyze the influence of the forcing scenario on the long-term evolution of the Greenland ice sheet and the AMOC. This is achieved by driving the same coupled climate-ice sheet model by a range of stabilized anthropogenic forcings. Such an analysis requires a large number of long-term integrations to be conducted. Therefore, an Earth system model of intermediate complexity is utilized. Models of this type are indeed much more computationally efficient than atmosphere-ocean general circulation models (AOGCMs). However, because of their reduced resolution and simplified representation of some physical processes, they only allow inferences about very large scales.

\section{Model and Experimental Design}

[5] LOVECLIM-1.0, the EMIC used here, consists of five components representing the atmosphere (ECBilt), the ocean and sea ice (CLIO), the terrestrial biosphere (VECODE), the oceanic carbon cycle (LOCH) and the Greenland and Antarctic ice sheets (AGISM). ECBilt is a quasi-geostrophic atmospheric model with 3 levels and a T21 horizontal resolution [Opsteegh et al., 1998]. It 


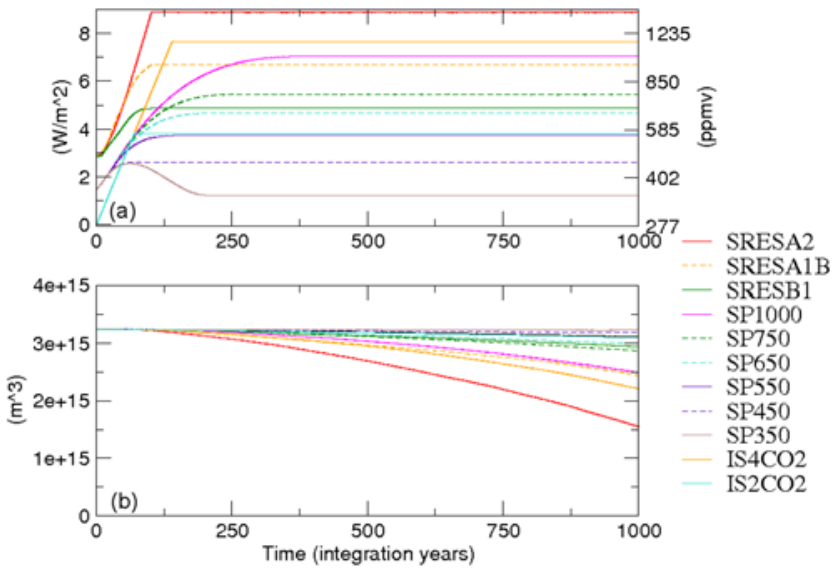

Figure 1. (a) Time series of the radiative forcing and (b) annual mean Greenland ice sheet volume for all experiments. Integration year 0 corresponds to the year $2000 \mathrm{AD}$ for SRES and SP experiments and to the year $1500 \mathrm{AD}$ for IS experiments. The equivalent $\mathrm{CO}_{2}$ concentrations are also given in Figure 1a following the IPCC [2001] formula: $\Delta \mathrm{F}=5.35 \ln \left(\mathrm{C} / \mathrm{C}_{0}\right)$, where $\mathrm{C}$ and $\mathrm{C}_{0}(=280 \mathrm{ppmv})$ are the current and reference $\mathrm{CO}_{2}$ concentrations, respectively, and $\Delta \mathrm{F}$ is the radiative forcing.

includes simple parameterizations of the diabatic heating processes and an explicit representation of the hydrological cycle. Cloud cover is prescribed according to present-day climatology, which is a limitation of the present study. CLIO is a primitive-equation, free-surface ocean general circulation model coupled to a thermodynamic-dynamic sea ice model [Goosse and Fichefet, 1999]. Its horizontal resolution is $3^{\circ} \times 3^{\circ}$, and there are 20 levels in the ocean. VECODE is a reduced-form model of vegetation dynamics and of the terrestrial carbon cycle [Brovkin et al., 2002]. It simulates the dynamics of two plant functional types (trees and grassland) at the same resolution as that of ECBilt. ECBilt-CLIO-VECODE has been utilized in a large number of climate studies (please refer to http://www.knmi.nl/ onderzk/CKO/ecbilt-papers.html for a full list of references). Interestingly enough, model intercomparison exercises have revealed that the response of the AMOC in ECBiltCLIO-VECODE to changes in greenhouse gas concentrations and to freshwater perturbations is close to the average one of current AOGCMs [Gregory et al., 2005; Stouffer et al., 2006]. LOCH is a comprehensive model of the oceanic carbon cycle [Mouchet and François, 1996]. It takes into account both the solubility and biological pumps, and runs on the same grid as the one of CLIO. Finally, AGISM is composed of a three-dimensional thermomechanical model of the ice sheet flow, a visco-elastic bedrock model and a model of the mass balance at the ice-atmosphere and iceocean interfaces [Huybrechts, 2002]. For both ice sheets, calculations are made on a $10 \mathrm{~km} \times 10 \mathrm{~km}$ resolution grid with 31 sigma levels.

[6] The atmospheric variables needed as an input for AGISM are surface temperature and precipitation. Because the details of the Greenland and Antarctica surface climates are not well captured on the ECBilt coarse grid, these boundary conditions consist of present-day observations as represented on the much finer AGISM grid onto which climate change anomalies from ECBilt are superimposed. Monthly temperature differences and annual precipitation ratios, computed against a reference climate corresponding to the period 1970-2000 $\mathrm{AD}$, are interpolated from the ECBilt grid onto the AGISM grid and added to and multiplied by the observed surface temperatures and precipitation rates, respectively. The oceanic heat flux at the base of Antarctic ice shelves is also calculated in perturbation mode using the parameterization proposed by Beckmann and Goosse [2003]. After performing mass balance and ice dynamic computations, AGISM transmits the calculated changes in land fraction covered by ice and orography to ECBilt and VECODE. In addition, AGISM provides CLIO with the geographical distribution of the annual mean surface freshwater flux resulting from ice sheet runoff, iceberg calving, runoff from ice-free land and basal ice melting. All of these sources of fresh water are added to the surface layer of coastal oceanic grid boxes. Some adjustments are regionally applied to the heat and freshwater fluxes to ensure conservation in the coupled system (see Driesschaert [2005] for details).

[7] The Greenland (Antarctic) ice sheet module was first integrated over the last two (four) glacial cycles up to $1500 \mathrm{AD}$ with forcing from ice core data to derive initial conditions for coupling with the other components of LOVECLIM-1.0. A control experiment (CTL) of 1000-year duration was then conducted with LOVECLIM-1.0 under forcing conditions corresponding to $1500 \mathrm{AD}$. Starting from the CTL quasi-equilibrium climate and the ice sheet configuration provided by the AGISM uncoupled run, LOVECLIM-1.0 was integrated up to $2000 \mathrm{AD}$ with solar irradiance, volcanic activity, greenhouse gas concentrations and sulphate aerosol load evolving with time according to reconstructions. Three climate change projections were then carried out with the greenhouse gas and sulphate aerosol forcings following the IPCC SRES scenarios A2, A1B and B1 for 100 years and held constant thereafter. Those experiments will hereafter be referred to as SRESA2, SRESA1B and SRESB1, respectively. The model was also driven from $1500 \mathrm{AD}$ by a range of $\mathrm{CO}_{2}$ stabilization profiles intended for the IPCC Fourth Assessment Report. The selected set of scenarios includes stabilization of atmospheric $\mathrm{CO}_{2}$ at levels of 350 (SP350), 450 (SP450), 550 (SP550), 650 (SP650), 750 (SP750) and 1000 (SP1000) ppmv. Two further experiments starting from the year 1500 conditions were performed. In IS2CO2 (IS4CO2), the $\mathrm{CO}_{2}$ concentration was increased by $1 \%$ per year (compounded) until it reached twice (four times) its initial value and remained unchanged afterwards. All the considered forcing scenarios are illustrated in Figure 1a. Since the $\mathrm{CO}_{2}$ concentration evolution was prescribed in all the simulations, the carbon cycle component of the model was used in a diagnostic mode, and its results will be discussed elsewhere.

\section{Climate, Ice-Sheet, and AMOC Response}

[8] In all of the projections but one, the annual average surface warming over Greenland rapidly exceeds $3^{\circ} \mathrm{C}$ and the Greenland ice sheet progressively looses mass (Figure 1b). After 1000 years of model integration, the ice volume is reduced by more than $20 \%$ when the radiative forcing is larger than $6.5 \mathrm{~W} \mathrm{~m}^{-2}$. Furthermore, for a 

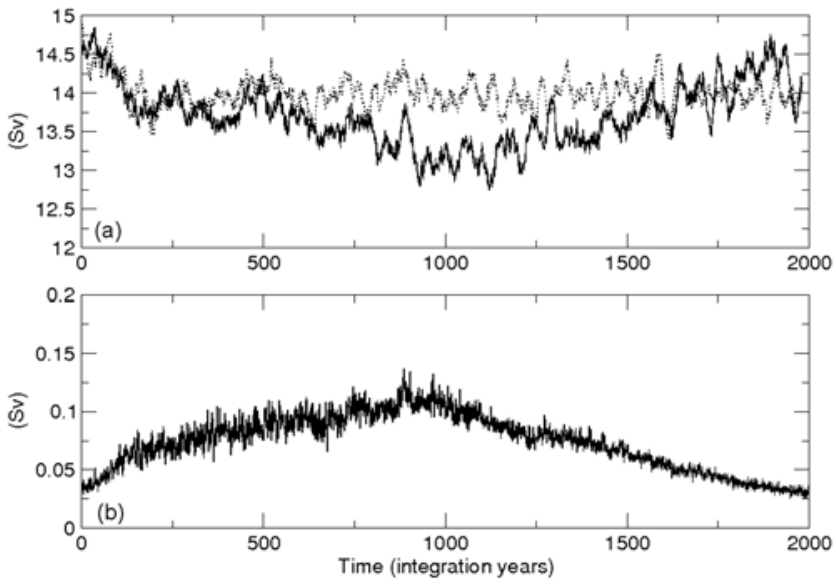

Figure 2. (a) Time series of the annual mean NADW export at $30^{\circ} \mathrm{S}$ in the Atlantic basin for SRESA2 (solid line) and SRESA2F (dotted line). (b) Time series of the annual mean freshwater flux from Greenland as simulated in SRESA2. Integration year 0 corresponds to year 2000 AD.

radiative forcing higher than $7.5 \mathrm{~W} \mathrm{~m}^{-2}$, which is reached in IS4CO2 and SRESA2, the ice sheet melts away in less than 3000 years. Such a disappearance of the Greenland ice sheet was also simulated by Ridley et al. [2005] with the same Greenland ice sheet coupled to an AOGCM and forced by an instantaneous quadrupling of the atmospheric $\mathrm{CO}_{2}$ concentration. The only experiment allowing for a stable ice sheet is SP350. However, stabilizing the $\mathrm{CO}_{2}$ concentration at $350 \mathrm{ppmv}$ in the next centuries, as in SP350, would require a drastic, reduction in anthropogenic $\mathrm{CO}_{2}$ emissions. Our results therefore suggest, in agreement with Gregory et al. [2004], that the potential melting of the Greenland ice sheet is serious.

[9] Once the volume of the modeled Greenland ice sheet is reduced by more than $35 \%$, the maximum surface warming over Greenland occurs in summer rather than in winter. Two major feedbacks contribute to this feature: the elevation-temperature feedback and the albedo-temperature feedback [Lunt et al., 2004; Toniazzo et al., 2004]. The adiabatic heating associated with the decrease in surface elevation is active throughout the year. By contrast, the albedo-temperature feedback mostly operates in summer, when insolation is largest. As the ice sheet recedes, the highly reflective ice is progressively replaced by vegetation with lower albedo. In order to quantify the influence of the latter feedback, a sensitivity experiment was performed. This experiment (SRESA2F) has the same forcing scenario as SRESA2, but neither the geometry nor the freshwater flux of both ice sheets are allowed to evolve. At the end of SRESA2, vegetation covers a large part of Greenland (grass is present everywhere, except in central Greenland, and trees are observed along the southern and eastern coasts) and the annual average surface temperature is increased there by $12.4^{\circ} \mathrm{C}$ compared to CTL. In SRESA2F, the corresponding warming (corrected for the direct effect of elevation change) is only $7.7^{\circ} \mathrm{C}$. Furthermore, the summer warming over Greenland in the latter run is weaker than the annual mean one.

[10] Changes in AMOC strength are generally small, except in the more extreme forcing scenarios. For the first
200 years of SRESA2, the annual mean export of North Atlantic Deep Water (NADW) at $30^{\circ} \mathrm{S}$ in the Atlantic basin (which is an index of the strength of the AMOC) decreases by $\sim 1 \mathrm{~Sv}$ (Figure 2a). A similar decrease is noticed in SRESA2F, indicating that the Greenland ice sheet melting has no impact on the AMOC over this time period. Actually, this decline of the AMOC mainly results from a decrease in surface heat loss in the northern North Atlantic caused by the greenhouse gas-induced warming [Gregory et al., 2005]. After the first 200 years of integration, the AMOC remains more or less stable in SRESA2F.

[11] In SRESA2, the annual mean freshwater flux from Greenland increases from $0.03 \mathrm{~Sv}$ at the beginning of the experiment (this value is close to the one for which the net mass balance of the ice sheet is zero in the model) to $0.11 \mathrm{~Sv}$ around integration year 1000 and remains above $0.1 \mathrm{~Sv}$ for about 300 years (Figure 2b). This slightly modifies the convection patterns and induces an extra $1 \mathrm{~Sv}$ decrease in the amount of NADW exported at $30^{\circ} \mathrm{S}$ (Figure 2a). After 1000 years of integration, the freshwater input from Greenland slowly diminishes with time, and the AMOC gradually recovers toward the SRESA2F state.

[12] The freshwater flux from the melting Greenland ice sheet is thus clearly insufficient to trigger a shutdown of the AMOC in LOVECLIM-1.0, which is consistent with the study of Ridley et al. [2005] as well as with climate change projections conducted with AOGCMs in which the meltwater input from the Greenland ice sheet is prescribed or only crudely parameterized [Jungclaus et al., 2006; Swingedouw et al., 2006]. It is also worth mentioning that none of the models used by Stouffer et al. [2006] in their intercomparison exercise simulates a shutdown of the AMOC in response to a $+0.1 \mathrm{~Sv}$ freshwater flux anomaly applied for 100 years to the northern North Atlantic Ocean. By contrast, Fichefet et al. [2003] found a strong and abrupt weakening of the AMOC due to the Greenland ice sheet melting at the end of the 21st century. However, these authors cautioned that the AMOC in their control run was too weak and probably very sensitive to a freshwater perturbation. A shutdown of the AMOC also occurred in the $4 \times \mathrm{CO}_{2}$ experiment carried out by Winguth et al. [2005] with their three-dimensional Earth system model. But, according to these authors, this feature was caused more by hydrological changes in the atmosphere than by the freshwater flux from the melting Greenland ice sheet.

[13] The relationship between the total freshwater flux from the ice sheet and the radiative forcing is highly nonlinear (Figure 3a). A radiative forcing of $4 \mathrm{~W} \mathrm{~m}^{-2}$ induces a small additional freshwater flux toward the ocean due to ice melting of about $0.01 \mathrm{~Sv}$ after 1000 years of integration compared to CTL. In contrast, when the radiative forcing is enhanced to $7 \mathrm{~W} \mathrm{~m}^{-2}$, the freshwater perturbation amounts to $0.05 \mathrm{~Sv}$. The non-linearity with the freshwater flux arises mainly because, in a warmer climate, the length of the ablation season increases in addition to the daily melt amount, giving a second-order dependence of total melt on the temperature rise. Also the increasing fraction of precipitation falling as rain contributes to the non-linearity as do the albedo and elevation feedbacks. Despite this non linearity in the freshwater flux forcing, Figure $3 b$ shows that the response of the AMOC intensity to the radiative forcing 
(a)

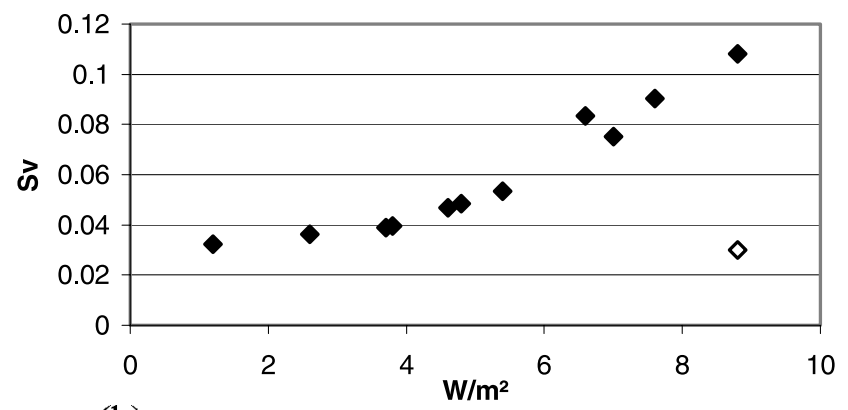

(b)

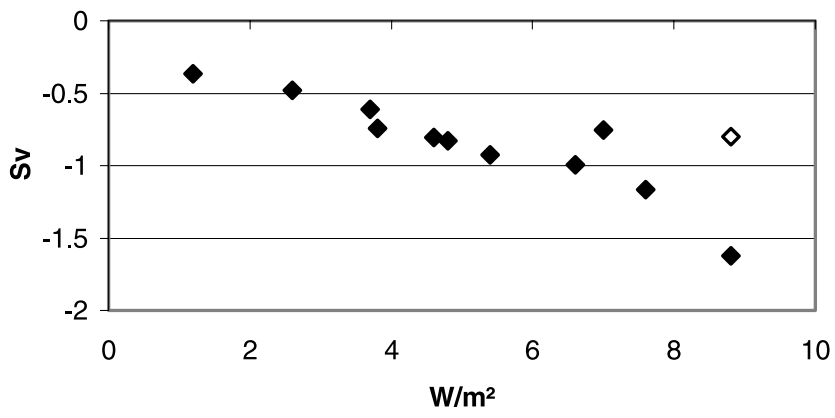

Figure 3. (a) Annual mean freshwater flux from Greenland averaged over integration years $950-1000$ as a function of the radiative forcing. (b) Change in annual mean NADW export at $30^{\circ} \mathrm{S}$ in the Atlantic basin averaged over integration years $950-1000$ as a function of the radiative forcing. The plotted changes are relative to the CTL value. In Figures $3 \mathrm{a}$ and $3 \mathrm{~b}$, each lozenge corresponds to one particular simulation (see Figure 1a), the empty lozenges correspond to SRESA2F.

is only slightly non-linear after 1000 years of integration for the range of forcings tested here.

\section{Conclusion}

[14] Our study suggests that, for a wide range of greenhouse gas stabilization profiles, the Greenland ice sheet volume should significantly decrease in the future. In the most extreme case considered here, which corresponds to a sustained radiative forcing of $\sim 8.5 \mathrm{~W} \mathrm{~m}^{-2}$, Greenland becomes ice-free in about 2000 years. This result should however be confirmed by using models of higher complexity. Note that ice sheet melting might even be more rapid if processes responsible for the widespread glacier acceleration currently observed in Greenland [e.g., Rignot and Kanagaratnam, 2006] were taken into account in the model. We also found that the freshwater flow from the melting Greenland ice sheet into the neighbouring oceans, which, for the most extreme forcing scenario selected, peaks at $0.11 \mathrm{~Sv}$ and remains above $0.1 \mathrm{~Sv}$ for three centuries, is not large enough to trigger a shutdown of the AMOC in our model. Only a slight decline of this circulation is simulated. Some models are, however, more responsive to freshwater perturbations than ours [e.g., Rahmstorf et al., 2005; Stouffer et al., 2006]. Finally, we showed that climate feedbacks considerably enhance the greenhouse gasinduced warming over Greenland and induce a highly non-linear response of the melting rate to the radiative forcing. This stresses the importance of incorporating the two-way interactions between the Greenland ice sheet and climate in climate and sea level change projections at the millennial time scale.

[15] Acknowledgments. We thank the two anonymous reviewers for their fruitful comments on the manuscript. Valuable comments on this work were also received from R.J. Stouffer and D. Swingedouw. H. Goosse and G. Munhoven are Research Associates at the Belgian Fund for Scientific Research. This study was funded by the Belgian Federal Science Policy within its Second Multiannual Support Plan for a Sustainable Development Policy and its Research Programme on Science for a Sustainable Development.

\section{References}

Beckmann, A., and H. Goosse (2003), A parameterization of ice shelfocean interaction for climate models, Ocean Modell. 5, pp. 157-170, Hooke Inst. Oxford Univ., Oxford, U. K.

Brovkin, V., J. Bendtsen, M. Claussen, A. Ganopolski, C. Kubatzki, V. Petoukhov, and A. Andreev (2002), Carbon cycle, vegetation, and climate dynamics in the Holocene: Experiments with the CLIMBER-2 model, Global Biogeochem. Cycles, 16(4), 1139, doi:10.1029/ 2001GB001662.

Dethloff, K., W. Dorn, A. Rinke, K. Fraedrich, M. Junge, E. Roeckner, V. Gayler, U. Cubash, and J. H. Christensen (2004), The impact of Greenland's deglaciation on the Arctic circulation, Geophys. Res. Lett., 31, L19201, doi:10.1029/2004GL020714.

Driesschaert, E. (2005), Climate change over the next millennia using LOVECLIM, a new Earth system model including the polar ice sheets, Ph.D. thesis, 214 pp., Univ. Catholique de Louvain, Louvain-la-Neuve, Belgium, http://edoc.bib.ucl.ac.be:81/ETD-db/collection/available/ BelnUcetd-10172005-185914/.

Fichefet, T., C. Poncin, H. Goosse, P. Huybrechts, I. Janssens, and H. Le Treut (2003), Implications of changes in freshwater flux from the Greenland ice sheet for the climate of the 21 st century, Geophys. Res. Lett., 30(17), 1911, doi:10.1029/2003GL017826.

Goosse, H., and T. Fichefet (1999), Importance of ice-ocean interactions for the global ocean circulation: A model study, J. Geophys. Res., 104, 23,337-23,355.

Gregory, J. M., P. Huybrechts, and S. C. B. Raper (2004), Threatened loss of the Greenland ice sheet, Nature, 428, 616 .

Gregory, J. M., et al. (2005), A model intercomparison of changes in the Atlantic thermohaline circulation in response to increasing atmospheric $\mathrm{CO}_{2}$ concentration, Geophys. Res. Lett., 32, L12703, doi:10.1029/ 2005 GL023209.

Greve, R. (2000), On the response of the Greenland ice sheet to greenhouse climate change, Clim. Change, 46, 289-303.

Holland, M. M., and C. M. Bitz (2003), Polar amplification of climate change in coupled models, Clim. Dyn., 21, 221-232, doi:10.1007 s00382-003-0332-6.

Huybrechts, P. (2002), Sea-level changes at the LGM from ice-dynamic reconstructions of the Greenland and Antarctic ice sheets during the glacial cycles, Quat. Sci. Rev., 21, 203-231.

Huybrechts, P., and J. de Wolde (1999), The dynamic response of the Greenland and Antarctic ice sheets to multiple-century climatic warming, J. Clim., 12, 2169-2188.

Huybrechts, P., I. Janssens, C. Poncin, and T. Fichefet (2002), The response of the Greenland ice sheet to climate changes in the 21 st century by interactive coupling of an AOGCM with a thermomechanical ice sheet model, Ann. Glaciol., 35, 409-415.

Intergovernmental Panel on Climate Change (IPCC) (2001), Climate Change 2001: The Scientific Basis: Contribution of Working Group I to the Third Assessment Report of the Intergovernmental Panel on Climate Change, edited by J. T. Houghton et al., 881 pp., Cambridge Univ. Press, Cambridge, U. K.

Jungclaus, J. H., H. Haak, M. Esch, E. Roeckner, and J. Marotzke (2006), Will Greenland melting halt the thermohaline circulation?, Geophys. Res. Lett., 33, L17708, doi:10.1029/2006GL026815.

Loutre, M. (1995), Greenland ice sheet over the next 5000 years, Geophys. Res. Lett., 22, 783-786.

Lunt, D. J., N de Noblet-Ducoudré, and S. Charbit (2004), Effects of a melted Greenland ice sheet on climate, vegetation, and the cryosphere, Clim. Dyn., 23, 679-694, doi:10.1007/s00382-004-0463-4.

Mouchet, A., and L. M. François (1996), Sensitivity of a global oceanic carbon cycle model to the circulation and to the fate of organic matter: Preliminary results, Phys. Chem. Earth, 21, 511-516. 
Opsteegh, J. D., R. J. Haarsma, F. M. Selten, and A. Kattenberg (1998), ECBILT: A dynamic alternative to mixed boundary conditions in ocean models, Tellus, Ser. A, 50, 348-367.

Rahmstorf, S., et al. (2005), Thermohaline circulation hysteresis: A model intercomparison, Geophys. Res. Lett., 32, L23605, doi:10.1029/ 2005 GL023655.

Ridley, J., P. Huybrechts, J. Gregory, and J. Lowe (2005), Future changes in the Greenland ice sheet: A 3000 year simulation with a high resolution ice sheet model interactively coupled to an AOGCM, J. Clim., 18, 34093427.

Rignot, E., and P. Kanagaratnam (2006), Changes in the velocity structure of the Greenland ice sheet, Science, 311, 986-990.

Stouffer, R. J., et al. (2006), Investigating the causes of the response of the thermohaline circulation to past and future climate changes, J. Clim., 19, $1365-1387$.

Swingedouw, D., P. Braconnot, and O. Marti (2006), Sensitivity of the Atlantic meridional overturning circulation to the melting from northern glaciers in climate change experiments, Geophys. Res. Lett., 33, L07711, doi:10.1029/2006GL025765.

Toniazzo, T., J. M. Gregory, and P. Huybrechts (2004), Climatic impact of a Greenland deglaciation and its possible irreversibility, J. Clim., 17 , $21-33$.
Winguth, A., U. Mikolajewicz, M. Gröger, E. Maier-Raimer, G. Schurgers, and M. Vizcaino (2005), Centennial-scale interactions between the carbon cycle and anthropogenic climate change using a dynamic Earth system model, Geophys. Res. Lett., 32, L23714, doi:10.1029/ 2005GL023681.

V. Brovkin, Climate Systems Research Department, Potsdam Institute for Climate Impact Research, P.O. Box 601203, D-14412 Potsdam, Germany. (victor@pik-potsdam.de)

E. Driesschaert, T. Fichefet, and H. Goosse, Institut d'Astronomie et de Géophysique Georges Lemaître, Université Catholique de Louvain, 2 chemin du Cyclotron, Louvain-la-Neuve B-1348, Belgium. (driess@ astr.ucl.ac.be; fichefet@astr.ucl.ac.be; hgs@astr.ucl.ac.be)

P. Huybrechts and I. Janssens, Departement Geografie, Vrije Universiteit Brussel, Pleinlaan 2, B-1050 Brussels, Belgium. (phuybrec@vub.ac.be; ivjansse@vub.ac.be)

A. Mouchet and G. Munhoven, Laboratoire de Physique Atmosphérique et Planétaire, Institut d'Astrophysique et de Géophysique, Université de Liège, Allée du 6 Août 17, Bat. B5c, B-4000 Liège, Belgium. (a.mouchet@ulg.ac.be; guy.munhoven@ulg.ac.be)

S. L. Weber, Royal Netherlands Meteorological Institute, P.O. Box 201, NL-3730 AE De Bilt, Netherlands. (weber@knmi.nl) 